\title{
Surgical ablation for atrial fibrillation for two decades: Are the results of new techniques equivalent to the Cox maze III procedure?
}

\author{
John M. Stulak, MD, Rakesh M. Suri, MD, DPhil, Harold M. Burkhart, MD, Richard C. Daly, MD, \\ Joseph A. Dearani, MD, Kevin L. Greason, MD, Lyle D. Joyce, MD, PhD, Soon J. Park, MD, and \\ Hartzell V. Schaff, MD
}

\begin{abstract}
Objectives: A significant evolution has occurred in surgical ablation for atrial fibrillation (AF) toward alternate energy sources, lesion sets, and approaches, with the intent of simplifying the Cox maze III operation and maintaining similar outcomes. Because no large comparative studies with long-term follow-up exist, we have reviewed our experience.
\end{abstract}

\begin{abstract}
Methods: From January 1993 to January 2011, 1540 patients underwent surgical ablation for AF. The operations were performed in conjunction with repair of congenital heart disease in $351(30 \%)$ and adult-acquired disease in 1189 patients $(70 \%)$. In the 1189 patients, preoperative AF was paroxysmal in $598(50 \%)$ and persistent in $591(50 \%)$. The energy sources included cut and sew in $521(44 \%)$, cryothermy in $267(22 \%)$, radiofrequency in $262(22 \%)$, and a combination in 139 patients $(12 \%)$. The lesion sets included biatrial in $810(68 \%)$, isolated pulmonary vein isolation in $269(23 \%)$, and isolated left atrial in $110(9 \%)$. AF ablation was performed during isolated mitral valve surgery in 516 patients $(43 \%)$.
\end{abstract}

Results: The median follow-up was 33 months (maximum, 20.3 years), and late rhythm follow-up was available for $80 \%$. The cut and sew Cox maze III procedure was superior at each follow-up interval $(P=.01, P=.03$, and $P<.001)$. On multivariate analysis, the cut and sew maze procedure was independently associated with less risk of recurrent $\mathrm{AF}$ at a follow-up period of 1 to 5 years (hazard ratio, $0.4 ; 95 \%$ confidence interval, 0.24-0.69; $P<.001$ ) and $>5$ years (hazard ratio, $0.23 ; 95 \%$ confidence interval, $0.12-0.42 ; P<.001$ ) for all patients. When performed during isolated mitral valve surgery, the cut and sew Cox maze III was also independently associated with less risk of recurrent $\mathrm{AF}$ at $>5$ years (hazard ratio, $0.23 ; 95 \%$ confidence interval, $0.08-0.66$; $P=.007)$.

Conclusions: The cut and sew Cox maze III procedure appears to offer significantly greater freedom from AF without antiarrhythmic medications compared with alternate energy sources and lesion sets. Although alternate energy sources offer the advantage of quicker application and the possibility of minimally invasive applications, the Cox maze III operation arguably remains the reference standard for the surgical treatment of AF and should still be considered, especially for patients for whom AF ablation is of critical importance. ( $\mathrm{J}$ Thorac Cardiovasc Surg 2014;147:1478-87)

Since its introduction, the cut and sew Cox maze III procedure has served as the reference standard for the surgical treatment of atrial fibrillation (AF). ${ }^{1-3}$ Rigorously evaluating the outcomes after the Cox maze III procedure was facilitated by the consistent nature of its lesion set and the absolute guarantee of obtaining transmural lesions. Since then, it has served as the foundation for the

From the Division of Cardiovascular Surgery, Mayo Clinic and Foundation, Rochester, Minn.

Disclosures: Authors have nothing to disclose with regard to commercial support.

Read at the 93rd Annual Meeting of The American Association for Thoracic Surgery, Minneapolis, Minnesota, May 4-8, 2013.

Received for publication May 6, 2013; revisions received Oct 13, 2013; accepted for publication Oct 22, 2013; available ahead of print Feb 21, 2014.

Address for reprints: John M. Stulak, MD, Division of Cardiovascular Surgery, Mayo Clinic College of Medicine, 200 First St SW, Rochester, MN 55905 (E-mail: stulak. john@mayo.edu).

$0022-5223 / \$ 36.00$

Copyright $($ C 2014 by The American Association for Thoracic Surgery

http://dx.doi.org/10.1016/j.jtcvs.2013.10.084 additional development and evolution of contemporary techniques for the surgical ablation of AF.

In the current era, the Cox maze III procedure has largely become a historical operation as various ablative energy sources and alternate lesion sets have become available and have been most commonly applied in practice. ${ }^{4}$ Subsequently, a rigorous evaluation of rhythm outcomes has become extremely challenging and plagued by heterogeneity. Thus, disagreement now exists regarding the optimal approach, whether it is type of energy source or which lesion set to be applied in what clinical setting. In addition, the underlying issue of reliably creating transmural lesions remains for every alternate ablative technology. Although consensus statements now exist in an effort to standardize the practice of surgical AF ablation and outcomes reporting, ${ }^{5,6}$ a lack of uniformity continues to exist in the published data, further complicating the assessment of current approaches. 


$$
\begin{aligned}
& \text { Abbreviations and Acronyms } \\
& \begin{aligned}
\text { AAM } & =\text { antiarrhythmic medication } \\
\text { AF } & =\text { atrial fibrillation } \\
\text { BA } & =\text { biatrial } \\
\text { CI } & =\text { confidence interval } \\
\text { CSM } & =\text { cut and sew Cox maze III procedure } \\
\text { HR } & =\text { hazard ratio } \\
\text { HRS } & =\text { Heart Rhythm Society } \\
\text { LA } & =\text { left atrial } \\
\text { NYHA } & =\text { New York Heart Association } \\
\text { PVI } & =\text { pulmonary vein isolation } \\
\text { RF } & =\text { radiofrequency }
\end{aligned}
\end{aligned}
$$

Because no large comparative series with long-term follow-up data have been published, we report our experience with the surgical treatment of AF for 2 decades. The goals of the present study were to (1) describe our surgical approach throughout the study period, (2) report the rhythm outcomes for all surgical approaches, and (3) identify the independent predictors associated with recurrent AF during early ( $<1$ year), midterm (1-5 years), and late $(>5$ years) follow-up.

\section{METHODS}

The Mayo Foundation institutional review board approved the present study, and all patients or their families provided written informed consent.

\section{Patients}

From March 5, 1993 to January 1, 2011, 1540 patients underwent surgical ablation for AF. Surgery for AF was performed in conjunction with repair of congenital heart disease in 351 patients $(30 \%)$ and adult-acquired disease in 1189 patients $(70 \%)$. The latter cohort of patients was the focus of the present review. The median age at surgery was 66 years (range, 22-91) and 707 were men (59\%). The type of preoperative AF was paroxysmal in 598 patients $(50 \%)$ and persistent in $591(50 \%)$.

The preoperative clinical characteristics include hypertension in 700 patients $(59 \%)$, hypercholesterolemia in $396(33 \%)$, congestive heart failure in $279(23 \%)$, and diabetes in $127(11 \%)$. Preoperatively, 116 patients $(10 \%)$ were in New York Heart Association (NYHA) functional class I, $373(31 \%)$ were in class II, $621(52 \%)$ were in class III, and 77 $(7 \%)$ were in class IV. The patients were analyzed as an entire cohort and separately according to the type of lesion set that was performed at surgery. These included biatrial (BA) in 810 patients $(68 \%)$, pulmonary vein isolation (PVI) alone in 269 (23\%), and complete left atrial (LA) in $110(9 \%)$. Additional delineations of preoperative clinical characteristics according to separate patient groups within the overall cohort are listed in Table 1 . Statistically significant differences were found among the study groups in terms of age $(P<.001)$, paroxysmal $\mathrm{AF}(P<.001)$, diabetes $(P=.028)$, and hypertension $(P<.001)$.

\section{Definitions}

We classified the type AF present according to the Heart Rhythm Society (HRS)/European Heart Rhythm Association/European Cardiac Arrhythmia Society Expert Consensus Statement, in collaboration with the American College of Cardiology, Society of Thoracic Surgeons, and American Heart Association. ${ }^{5,6}$ Paroxysmal AF was defined by recurrent $(\geq 2)$ episodes of AF that were self-terminating. Persistent AF was defined by a continuous episode of AF that was present for $>7$ days or $<7$ days but required medical or electrical conversion. Longstanding persistent $\mathrm{AF}$ was considered present when a patient had continuous $\mathrm{AF}$ for $>1$ year. We have reported success as freedom from $\mathrm{AF}$ without antiarrhythmic medications (AAMs), also in accordance with the consensus statement.

\section{Surgical Ablation Descriptions}

For the cut and sew Cox maze III procedure (CSM), the lesions were performed as described by Cox and colleagues, ${ }^{1}$ using cardiopulmonary bypass with normothermia or moderate hypothermia $\left(28^{\circ}-32^{\circ} \mathrm{C}\right)$. We used 2 minor modifications to the original Cox maze procedure, as we have reported previously. ${ }^{3}$ Cryoablation was performed using a variety of probes, including Frigitronics (CooperVision, Inc, Lake Forest, Calif) and CryoCath (Medtronic, Montreal, Quebec, Canada). Cryolesions were created with the cryoprobe for $\geq 1$ minute (maximum, 2.5 ) at $-60^{\circ} \mathrm{C}$. With bipolar radiofrequency (RF), the device gave feedback when the lesion was transmural, and a minimum of 2 applications were applied. Depending on the quality and thickness of the atrial tissue, multiple applications were often used. Bipolar RF was performed using either the AtriCure device (AtriCure, Inc, Cincinnati, Ohio) or the Cardioblate device (Medtronic, Inc, Minneapolis, Minn). The lesion sets employed using these alternate energy sources were (1) isolated PVI, achieved from either an epicardial approach isolating each side separately or an endocardial approach and including all veins within a box; (2) a LA lesion set, which added a connecting lesion to the LA appendage and to the mitral valve annulus from the PVI line, and included cryoablation at the mitral valve annulus; and (3) a complete BA lesion set, which mimicked the Cox maze III lesions, more recently termed the "Cox maze IV" procedure. Importantly, we have continued to use cryolesions at the mitral and tricuspid valve annuli and to create the transseptal lesion, similar to our approach in the standard Cox maze III procedure.

\section{Postoperative Care}

The potassium and magnesium levels were maintained in the high normal range, and diuretics were used early after surgery, as needed, to prevent fluid retention. If postoperative $\mathrm{AF}$ occurred, the patients were treated with amiodarone and electrical cardioversion was used as needed; amiodarone was then continued for 3 months. All patients were dismissed with warfarin and advised to continue anticoagulation for a minimum of 3 months. The continuation or discontinuation of warfarin or AAMs was at the discretion of the patient's primary cardiologist or primary care physician, depending on the clinical setting and cardiac rhythm.

\section{Follow-up Data}

The demographic and other patient-related data were obtained from the Mayo Clinic medical records and our prospective clinical database. Follow-up information was obtained from subsequent clinic visits, written correspondence from local physicians, and mailed questionnaires to the patients or families. The rhythm was evaluated using an electrocardiogram (ECG) obtained $\geq 3$ months after surgery; this served as the blanking period.

\section{Statistical Analysis}

Continuous data are expressed as either the mean \pm standard deviation or median and range. The data between 2 groups were compared using Student's paired $t$ test, and the data among $>2$ groups were compared using 1 -way analysis of variance. The risk factors were assessed using log-rank analysis. The variables significant on univariate analysis were used during stepwise selection to create the final multivariate model. Early operative mortality was defined as death occurring within 30 days of surgery or at any point during the index hospitalization. Analysis was performed on the entire patient cohort and the separate patient cohorts according to the 
TABLE 1. Preoperative clinical characteristics

\begin{tabular}{lccccr}
\hline $\begin{array}{c}\text { Clinical } \\
\text { variable }\end{array}$ & $\begin{array}{c}\text { CSM } \\
(\mathbf{n}=\mathbf{5 1 4})\end{array}$ & $\begin{array}{c}\text { PVI } \\
(\mathbf{n}=\mathbf{2 6 9})\end{array}$ & $\begin{array}{c}\text { LA } \\
(\mathbf{n}=\mathbf{1 1 0})\end{array}$ & $\begin{array}{c}\text { BA-A } \\
(\mathbf{n}=\mathbf{2 9 6})\end{array}$ & $\begin{array}{c}\boldsymbol{P} \\
\text { value }\end{array}$ \\
\hline Age & 62 & 68 & 68 & 68 & $<.001$ \\
Paroxysmal AF & $172(33)$ & $218(81)$ & $82(75)$ & $126(43)$ & $<.001$ \\
Diabetes & $9(8)$ & $36(13)$ & $11(10)$ & $40(14)$ & .028 \\
Hypertension & $267(52)$ & $185(69)$ & $65(59)$ & $182(61)$ & $<.001$ \\
\hline
\end{tabular}

Data presented as n (\%). CSM, Cut and sew Cox maze III procedure; $P V I$, pulmonary vein isolation; $L A$, left atrial; $B A-A$, biatrial with alternative sources of energy; $A F$, atrial fibrillation.

type of lesion set performed, including the CSM, isolated PVI, LA lesion set, and BA lesion set using alternate energy sources. The analysis of outcomes was performed for patients for whom follow-up data were available. The patients were censored and not included in the postoperative analysis if follow-up data were unable to be obtained.

\section{RESULTS \\ Operative Data}

All patients underwent surgical ablation of AF. For the entire cohort, the lesion sets performed included BA in 810 patients $(68 \%)$, PVI alone in $269(23 \%)$, and complete LA in $110(9 \%)$. For the 810 patients who received a BA lesion set, the CSM was performed in 514 patients $(63 \%)$ and alternate energy sources were used to mimic the classic Cox maze III lesions in 296 (37\%). The energy sources used for the creation of lesions included CSM in 521 patients $(44 \%)$, cryothermy in $267(22 \%)$, RF in 262 $(22 \%)$, and a combination of energy sources in $139(12 \%)$.

For the 269 patients who underwent isolated PVI, the energy sources included CSM in 2 patients $(1 \%)$, RF in $181(67 \%)$, cryothermy in $67(25 \%)$, and a combination in $19(7 \%)$. For the 110 patients who underwent an LA lesion set, the energy sources included CSM in 5 patients $(5 \%), \mathrm{RF}$ in $25(23 \%)$, cryothermy in $55(50 \%)$, and a combination in $25(22 \%)$. For the 296 patients who underwent a BA lesion set using alternate technology, the energy sources included RF in 56 patients $(19 \%)$, cryothermy in 144 (49\%), and a combination in $95(32 \%)$.

The cardiac operations performed during surgical ablation of AF included mitral valve surgery in 713 patients $(60 \%)$, coronary artery bypass grafting in $257(22 \%)$, tricuspid valve surgery in $205(17 \%)$, and aortic valve surgery in $190(16 \%)$. The LA appendage was amputated or ligated in 1008 patients $(84 \%)$. The median crossclamp time was 59 minutes (range, 13-376), and the median cardiopulmonary bypass time was 92 minutes (range, 11-579). Additional delineations of the operative data stratified according to the lesion set performed are listed in Table 2. Statistically significant differences were present among the study groups in terms of mitral valve surgery $(P<.001)$, crossclamp time $(P<.001)$, bypass time $(P<.001)$, and LA appendage ligation $(P<.001)$.

The approaches to surgical AF ablation evolved during the study period. The types of lesion sets performed
TABLE 2. Operative characteristics

\begin{tabular}{|c|c|c|c|c|c|}
\hline Operative variable & $\begin{array}{c}\text { CSM } \\
(n=514)\end{array}$ & $\begin{array}{c}\text { PVI } \\
(n=269)\end{array}$ & $\begin{array}{c}\text { LA } \\
(\mathbf{n}=\mathbf{1 1 0})\end{array}$ & $\begin{array}{c}\text { BA-A } \\
(n=296)\end{array}$ & $\begin{array}{c}P \\
\text { value }\end{array}$ \\
\hline MV & $308(60)$ & $105(39)$ & $96(87)$ & 204 (69) & $<.001$ \\
\hline $\begin{array}{l}\text { Crossclamp } \\
\text { time (min) }\end{array}$ & $59 \pm 5$ & $65 \pm 6$ & $81 \pm 6$ & $85 \pm 6$ & $<.001$ \\
\hline Bypass time (min) & $103 \pm 7$ & $90 \pm 8$ & $109 \pm 7$ & $119 \pm 7$ & $<.001$ \\
\hline LAA ligation & $514(100)$ & $188(70)$ & $88(80)$ & $218(74)$ & $<.001$ \\
\hline
\end{tabular}

Data presented as n $(\%)$ or mean \pm standard deviation. CSM, Cut and sew Cox maze III procedure; $P V I$, pulmonary vein isolation; $L A$, left atrial; $B A-A$, biatrial with alternative sources of energy; $M V$, mitral valve; $L A A$, left atrial ablation.

according to year are shown in Figure 1. An increase occurred in the focal lesion sets (PVI and LA) through the study period. The energy sources used according to year are shown in Figure 2. An increase in the alternate energy sources (RF, cryothermy, and combined) through the study period. The use of the classic CSM procedure according to year is shown in Figure 3. However, an increase in the use of alternative lesion sets and energy sources was seen through the study period.

\section{Early Outcomes}

Early nonfatal morbidity for the entire cohort included re-exploration for bleeding in 58 patients $(4.9 \%)$, new permanent pacemaker placement in $44(3.7 \%)$, renal failure in $37(3 \% ; 23$ required dialysis), superficial wound infection in $13(1.1 \%)$, and neurologic events in 13 $(1.1 \% ; 11$ with stroke and 2 with transient ischemic attack). Seventy-four early deaths $(6.2 \%)$ occurred. The delineation of the early postoperative outcomes stratified according to lesion set performed is listed in Table 3 .

\section{Follow-up}

For the entire cohort, the median follow-up period was 34 months (range, 3 month to 20.4 years), and rhythm follow-up data were available for 891 of the 1115 early survivors $(80 \%)$ for a median of 38 months (range, 5 months to 18.5 years). The median length of rhythm follow-up varied significantly among patients who underwent differing surgical approaches to $\mathrm{AF}$ ablation: CSM (57 months; range, 3 months to 18.5 years), PVI (30 months; range 3 months to 8 years), LA (26 months; range 3 months to 10.2 years), and BA with alternative energy sources ( 26 months; range, 3 months to 9.5 years; $P<.001)$.

\section{Rhythm Outcomes}

Freedom from AF without AAMs at the last follow-up point for the entire cohort was $72 \%$; after CSM, isolated PVI, LA, and BA with alternative energy sources was $80 \%, 63 \%, 78 \%$, and $61 \%$, respectively $(P<.001)$. Because significant disparities existed in the follow-up duration, we analyzed the freedom from $\mathrm{AF}$ without 


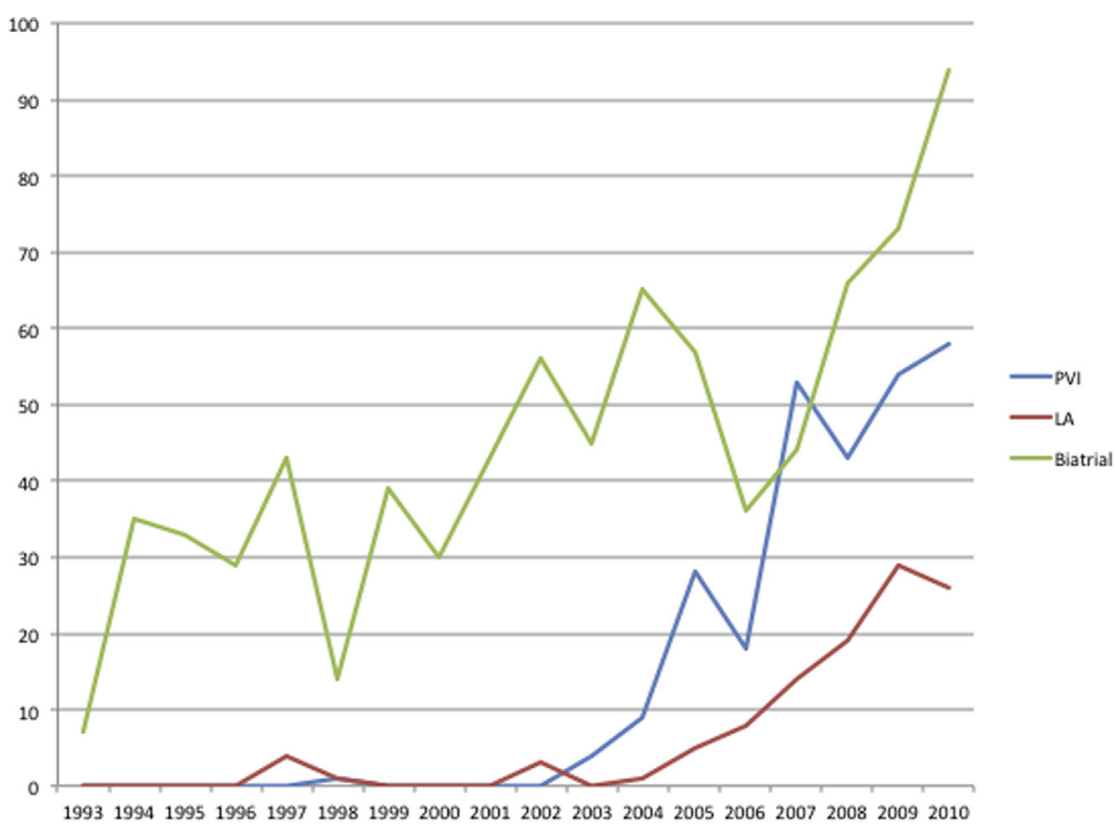

FIGURE 1. Types of lesion sets performed according to year. An increase was seen in focal lesion sets (pulmonary vein isolation $[P V I]$ and left atrial $[L A]$ ) throughout the study period.

AAMs at 3 different intervals: $<1,1$ to 5 , and $>5$ years. The most recent ECG available during each interval was used for rhythm analysis. The overall freedom from AF without AAM rate at each follow-up interval according to the type of ablative energy source is presented in Figure 4. CSM was superior at $<1,1$ to 5 , and $>5$ years $(P=.01$, $P=.03$, and $P<.001$, respectively). The rate of overall freedom from $\mathrm{AF}$ without AAM at each follow-up interval according to the type of lesion set is presented in Figure 5. The BA and complete LA lesion sets were superior at $>5$ years after surgery $(P=.004)$. The Cox maze III procedure was associated with significantly greater freedom from $\mathrm{AF}$ without AAM compared with the BA lesion set performed with alternate energy sources $(80 \%$ vs $61 \%, P<.001)$.

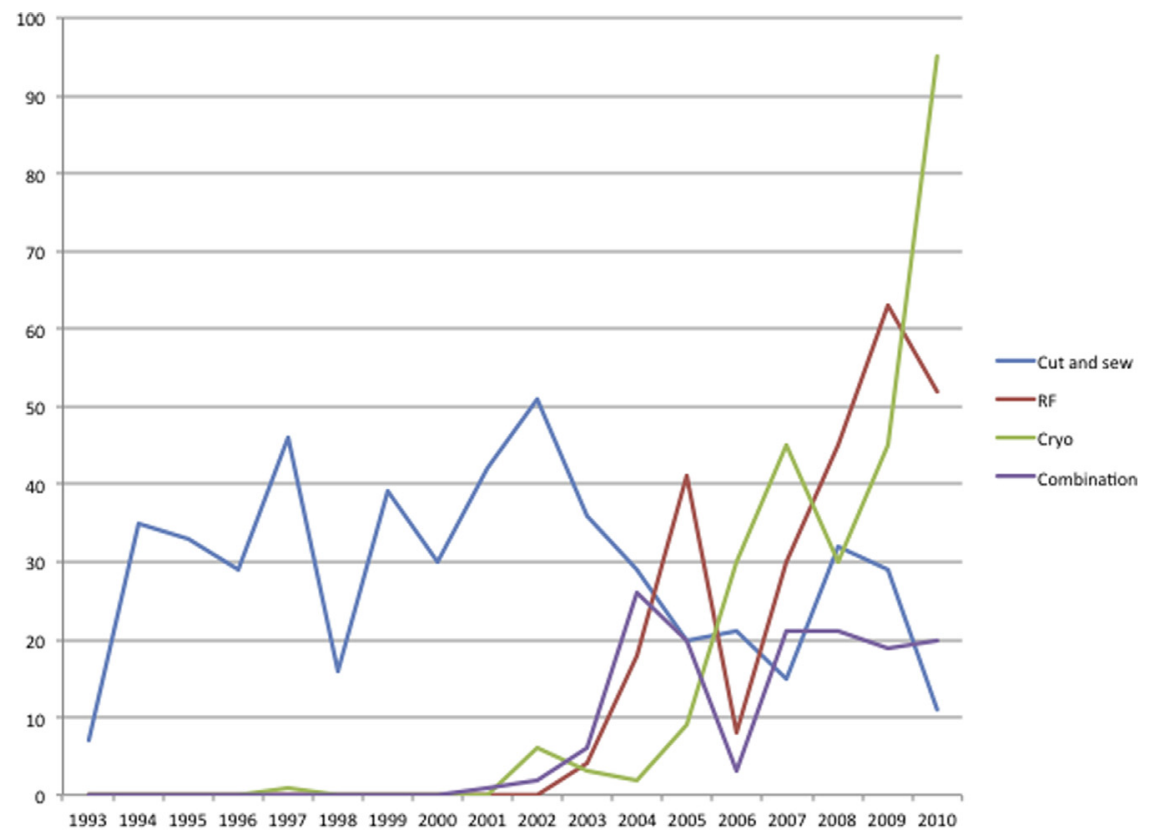

FIGURE 2. Energy sources used according to year. An increase was seen in alternate energy sources (radiofrequency [RF], cryothermy [Cryo], and combined) through the study period. 


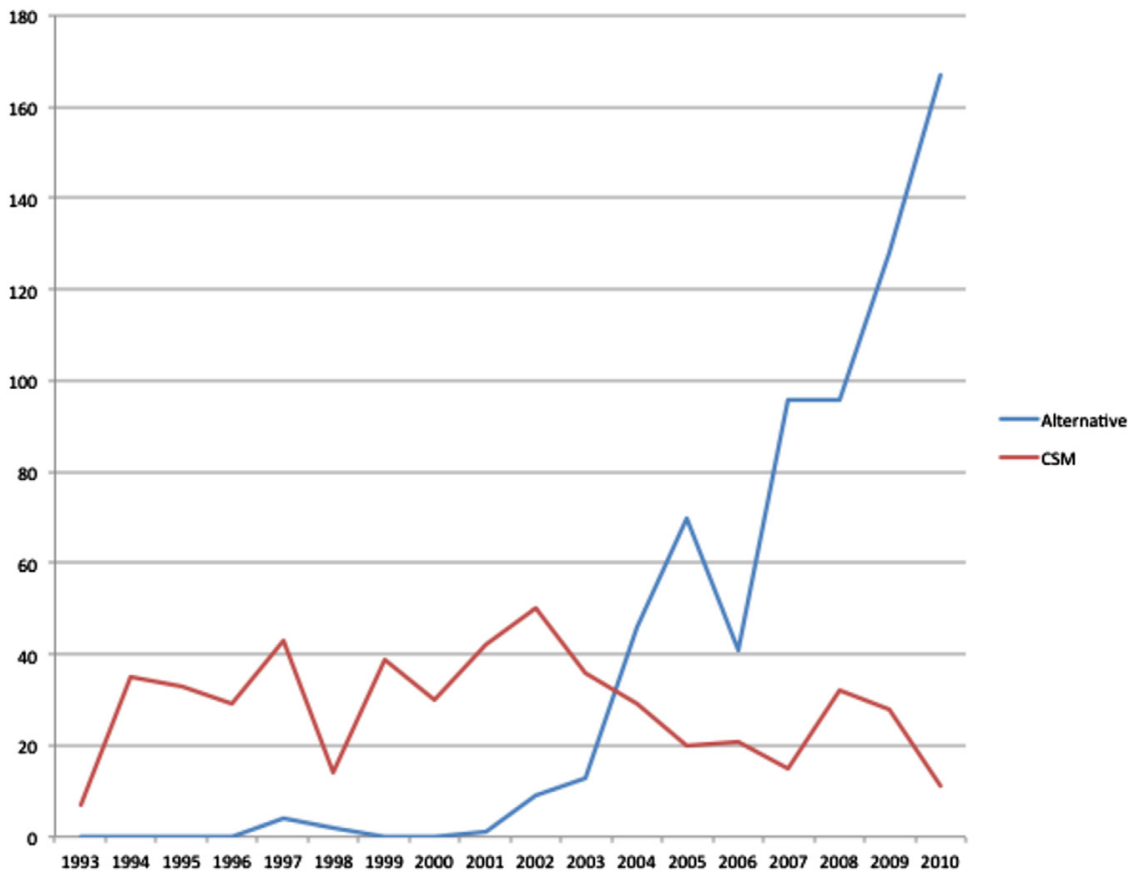

FIGURE 3. The use of the classic cut and sew Cox maze III (CSM) procedure according to year. An increase was seen in the use of alternative lesion sets and energy sources throughout the study period.

We adjusted for patient differences in the patient populations by performing a stepwise backward multivariate logistic regression analysis. For the entire cohort, $<1$ year after surgical AF ablation age (per 5 years; hazard ratio $[\mathrm{HR}], 1.44 ; 95 \%$ confidence interval $[\mathrm{CI}], 1.2-1.7$; $P<.001)$ was independently associated with less freedom from AF without AAMs. At 1 to 5 years after surgery, preoperative paroxysmal AF (HR, 0.33; 95\% CI, 0.2-0.5; $P<.001$ ), the Cox maze III operation (HR, 0.4; 95\% CI, 0.2-0.7; $P<.001$ ), and isolated mitral valve surgery (HR, 0.6; 95\% CI, 0.4-0.96; $P=.03$ ) were independently associated with greater freedom from AF without AAMs. Age (per 5 years; HR, 1.11; 95\% CI, 1-1.2; $P=.048$ ) was independently associated with less freedom from AF without AAMs. At follow-up $>5$ years, the Cox maze III operation (HR, 0.23; 95\% CI, 0.12-0.42; $P<.001$ ) and preoperative paroxysmal $\mathrm{AF}(\mathrm{HR}, 0.36 ; 95 \% \mathrm{CI}$,

TABLE 3. Early nonfatal morbidity

\begin{tabular}{lccccc}
\hline \multicolumn{1}{c}{ Early outcome } & $\begin{array}{c}\text { CSM } \\
(\mathbf{n}=\mathbf{5 1 4})\end{array}$ & $\begin{array}{c}\text { PVI } \\
(\mathbf{n}=\mathbf{2 6 9})\end{array}$ & $\begin{array}{c}\text { LA } \\
(\mathbf{n}=\mathbf{1 1 0})\end{array}$ & $\begin{array}{c}\text { BA-A } \\
(\mathbf{n}=\mathbf{2 9 6})\end{array}$ & $\begin{array}{c}\boldsymbol{P} \\
\text { value }\end{array}$ \\
\hline $\begin{array}{l}\text { Reoperation for } \\
\quad 3(\text { leeding }\end{array}$ & $33(6)$ & $8(3)$ & $1(1)$ & $16(5)$ & .04 \\
$\begin{array}{l}\text { Postoperative stroke } \\
\text { Renal failure }\end{array}$ & $6(1)$ & $2(1)$ & $0(0)$ & $4(1)$ & $<.66$ \\
Early PPM & $10(2)$ & $9(3)$ & $3(3)$ & $15(5)$ & .13 \\
Early death & $12(2)$ & $7(3)$ & $3(3)$ & $22(7)$ & .003 \\
\hline Dat & $12(2)$ & $28(10)$ & $12(11)$ & $22(7)$ & $<.001$ \\
\hline
\end{tabular}

Data presented as $\mathrm{n}(\%)$ or mean \pm standard deviation. CSM, Cut and sew Cox maze III procedure; $P V I$, pulmonary vein isolation; $L A$, left atrial; $B A-A$, biatrial with alternative sources of energy; $P P M$, permanent pacemaker.
$0.2-0.66 ; P=.001)$ were independently associated with greater freedom from AF without AAMs, and preoperative NYHA functional class III-IV (HR, 1.84; 95\% CI, $1.04-3.27 ; P=.036$ ) was independently associated with less freedom from AF without AAMs.

\section{Isolated Mitral Valve Surgery}

Patients undergoing isolated mitral valve surgery and concomitant surgical ablation of AF represented the largest single patient cohort $(\mathrm{n}=516)$. Thus, to attempt to adjust for confounders, we also analyzed this subgroup. The energy sources used to create lesions included CSM in 266 patients $(52 \%), \mathrm{RF}$ in $73(14 \%)$, cryothermy in 113 $(22 \%)$, and a combination in $64(12 \%)$. Paroxysmal AF was present in 234 patients $(45 \%)$ ). The lesion sets included PVI in 68 patients (13\%), LA in $79(15 \%)$, and BA in 369 $(72 \%)$. The classic Cox maze III procedure was performed in 256 patients $(50 \%)$. The overall freedom from $\mathrm{AF}$ without AAMs was $71 \%$. The rhythm outcome stratified according to the interval of follow-up and type of ablative energy performed is presented in Figure 6. CSM was associated with significantly greater freedom from $\mathrm{AF}$ without AAMs after 5 years postoperatively $(P=.03)$. The overall freedom from AF without AAMs at each follow-up interval according to the type of lesion set demonstrated no difference at any follow-up point $(P=.1, P=.5$, and $P=.8)$. However, patients undergoing the Cox maze III procedure concurrent with isolated mitral valve surgery resulted in significantly greater freedom from 


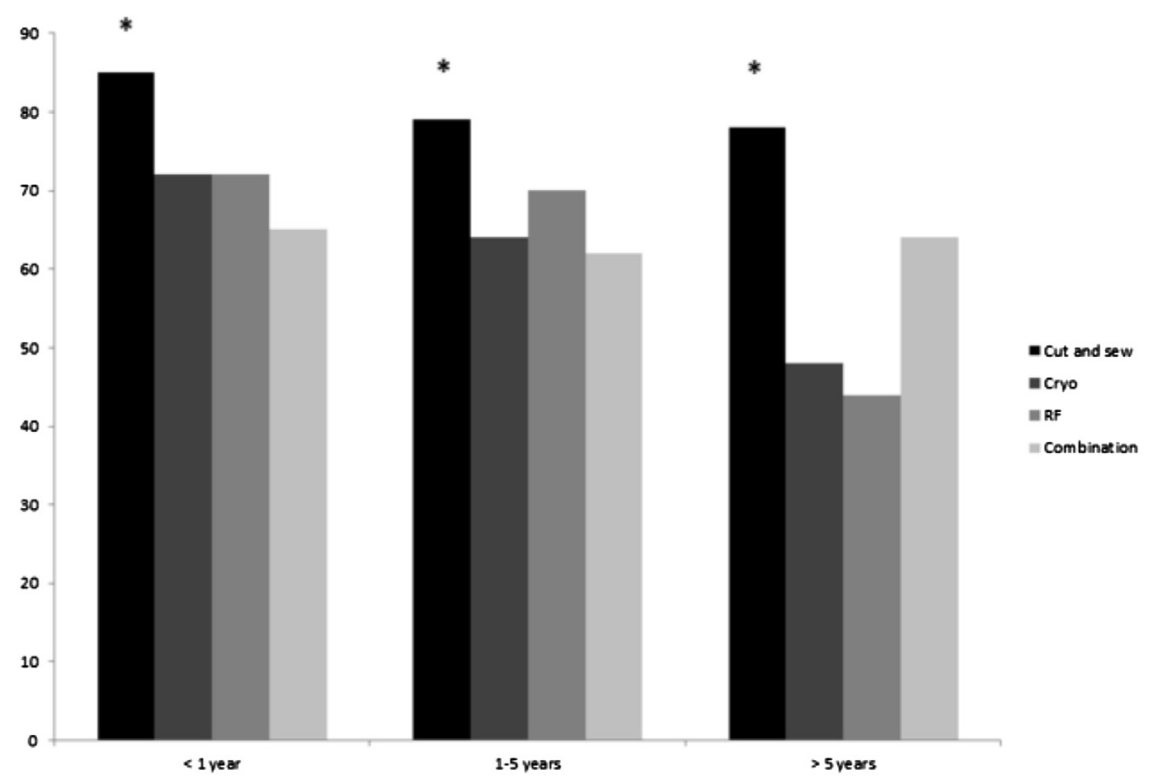

FIGURE 4. Overall freedom from atrial fibrillation without antiarrhythmic medication (\%) at each follow-up point according to type of ablative energy source. Cut and sew was superior at each follow-up interval $(P=.01, P=.03$, and $P<.001$, respectively). Cryo, Cryothermy; $R F$, radiofrequency. *Statistically significant difference.

AF without AAMs compared with any other procedure for AF ablation within 1 year postoperatively ( $87 \%$ vs $70 \%$, $P=.04)$ and after 5 years postoperatively $(75 \%$ vs $52 \%$, $P=.03)$.

Less than 1 year after surgical $\mathrm{AF}$ ablation, female gender (HR, 4.9; 95\% CI, 1.03-23.02; $P=.045$ ) was independently associated with less freedom from AF without AAMs. At 1 to 5 years of follow-up, preoperative paroxysmal AF (HR, 0.25; 95\% CI, 0.11-0.58; $P=.0013)$ independently predicted greater freedom from AF without AAMs and female gender (HR, 2.34; 95\% CI, 1.01-5.4; $P=.046$ ), less freedom from AF without

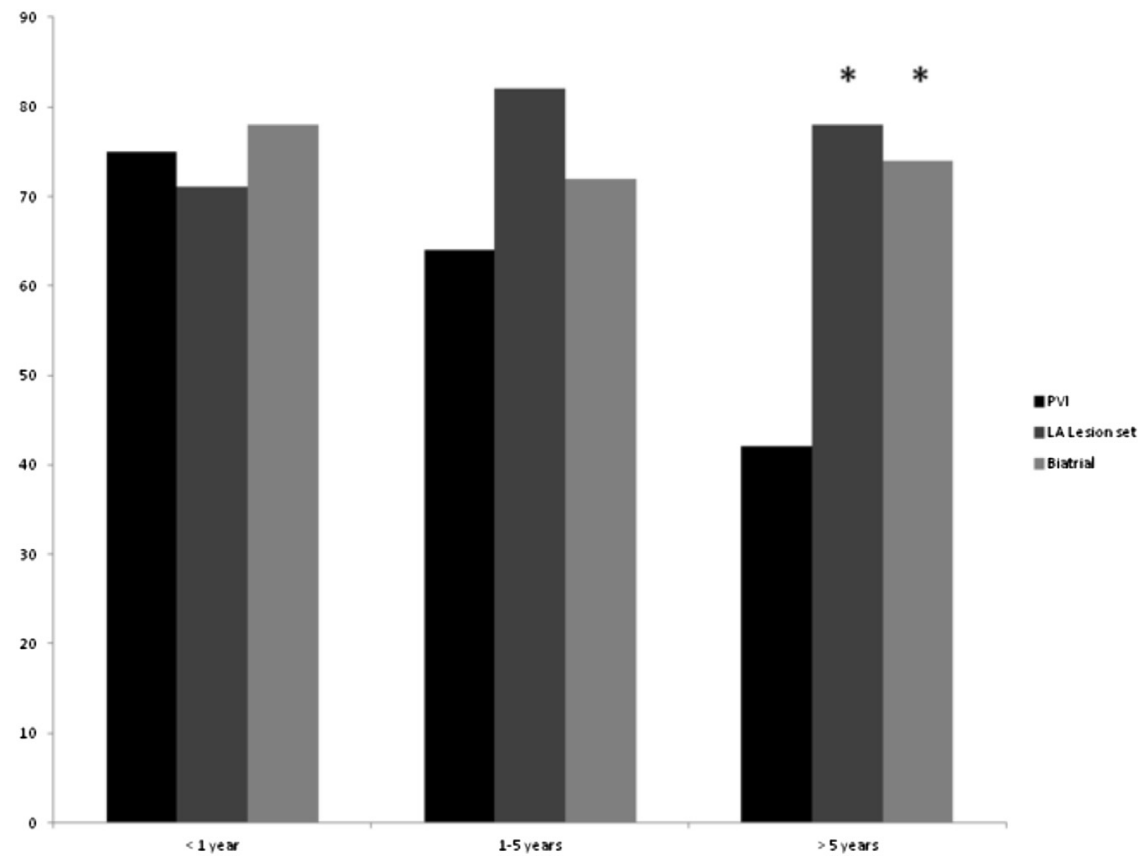

FIGURE 5. Overall freedom from atrial fibrillation without antiarrhythmic medication (\%) at each follow-up interval according to the type of lesion set. Biatrial and complete left atrial $(L A)$ lesion sets were superior at $>5$ years postoperatively $(P=.004)$. * Statistically significant difference. $P V I$, Pulmonary vein isolation. 


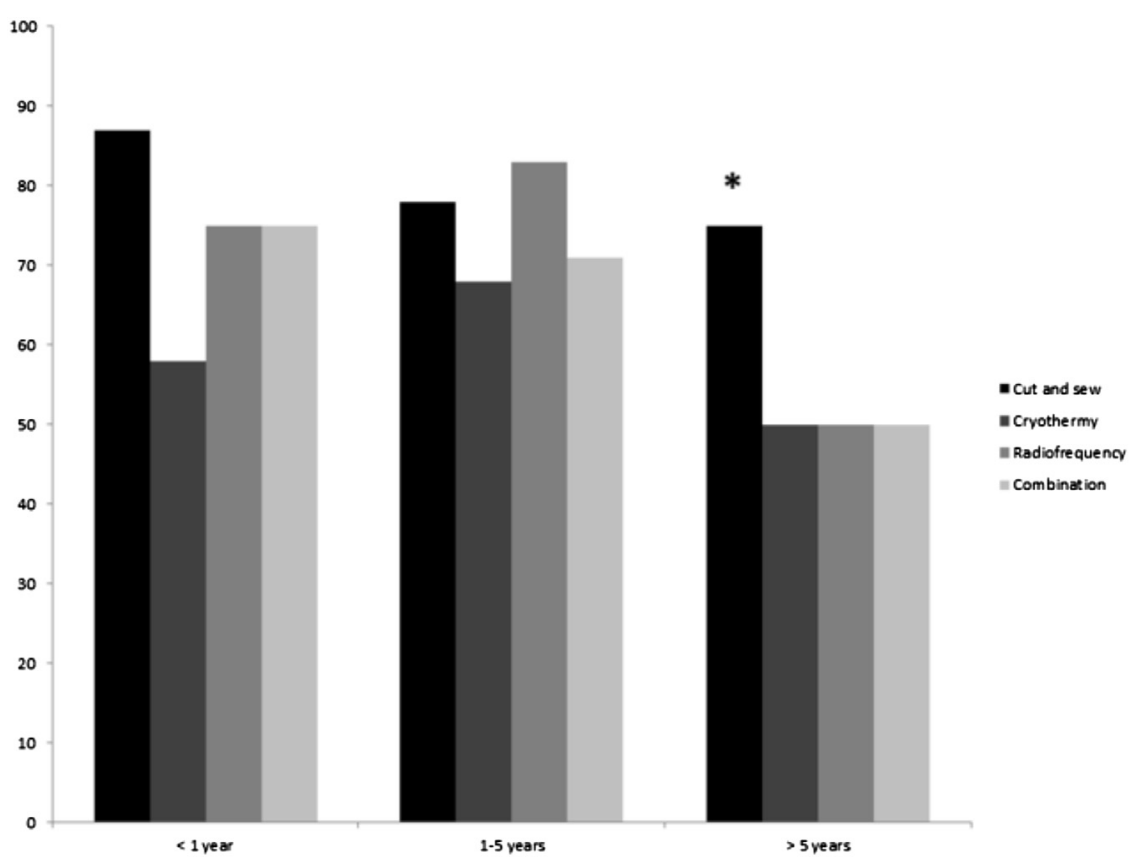

FIGURE 6. Freedom from atrial fibrillation without antiarrhythmic medication (\%) at each follow-up interval according to type of ablative energy performed for patients who underwent isolated mitral valve surgery. Cut and sew was associated with significantly greater freedom from atrial fibrillation without antiarrhythmic medication after 5 years postoperatively $(P=.03)$ * Statistically significant difference.

AAMs. At $>5$ years of follow-up, the Cox maze III operation (HR, 0.23; 95\% CI, 0.08-0.66; $P=.007$ ) and preoperative paroxysmal $\mathrm{AF}$ (HR, $0.27 ; 95 \% \mathrm{CI}$, $0.1-0.71 ; P=.009)$ independently predicted greater freedom from $\mathrm{AF}$ without AAMs, and preoperative NYHA functional class III-IV (HR, 2.86; 95\% CI, $1.14-7.17 ; P=.025$ ) was independently associated with less freedom from AF without AAMs.

\section{DISCUSSION}

We have demonstrated that freedom from $\mathrm{AF}$ without AAMs will be significantly greater in patients undergoing the Cox maze III procedure than in patients undergoing surgical AF ablation with alternate energy sources and lesion sets at all follow-up points. Furthermore, for all patients, the Cox maze III procedure was independently associated with greater freedom from AF without AAMs $>1$ year postoperatively on multivariate analysis. Freedom from $\mathrm{AF}$ without AAMs was significantly greater at late follow-up for patients undergoing isolated mitral valve surgery and the concomitant Cox maze III procedure.

The evolution of our practice has mirrored that of the contemporary cardiac surgical community, ${ }^{8}$ with significantly more patients undergoing surgical AF ablation with alternate lesion sets (Figure 1) and alternate energy sources (Figure 2) compared with the Cox maze III procedure (Figure 3). In analyzing our large experience, we encountered challenges similar to those of others, in that the present series was heterogeneous, with multiple subgroups requiring analysis. We have previously performed and reported a case-matched series evaluating new technologies compared with the Cox maze III procedure; however, we did not do this in the present series. ${ }^{9}$ To account for the varying patient characteristics, lesion sets, and energy sources, we used a multivariate model to identify the independent predictive factors. With so many permutations of patient subgroups (eg, preoperative AF type, energy source, lesion set, type of concomitant cardiac surgical procedure), the small numbers in each subgroup detracted from a meaningful and robust subgroup analysis. We did analyze our largest patient subgroup, and, arguably, the most relevant in clinical practice for surgical AF ablation. Our largest subgroup was the patients who underwent mitral valve surgery and concomitant surgical AF ablation. Even within this subgroup, the indications, and procedures performed, for mitral valve pathologic features were heterogeneous. These challenges will continue in the analysis of surgical $\mathrm{AF}$ ablation; however, an honest attempt to control for these differences will continue to be of paramount importance.

For all patients, we observed that CSM as an energy source was associated with greater freedom from $\mathrm{AF}$ without AAMs at all follow-up points after surgery compared with alternate energy sources (RF, cryothermy, or a combination). In terms of the lesion sets, a complete LA and BA lesion set were associated with greater success at $>5$ years of postoperative follow-up. The Cox maze III procedure was significantly more effective than the PVI 
and LA lesion set during all follow-up points. However, because this was not a fair comparison of similar procedures, we more specifically examined the Cox maze III procedure compared with the BA lesion set performed with alternate energy sources (RF, cryothermy, or a combination). The classic Cox maze III procedure resulted in significantly greater freedom from AF without AAMs in this setting. After accounting for the confounders, on multivariate analysis, the Cox maze III procedure was independently associated with greater success $>1$ year after surgery. For patients undergoing isolated mitral valve surgery and concomitant AF ablation, neither the lesion set nor the energy source yielded a greater success rate of AF ablation compared with one another on its own. However, when a Cox maze III procedure was performed, the success within 1 year and after 5 years postoperatively was significantly greater.

New technologies and new approaches have been aimed at simplifying lesion sets and shortening the time needed to create atrial ablation lines ${ }^{7}$ compared with the technical complexity associated with the Cox maze III procedure. Consequently, the issue of ensuring completely transmural lesions remains unresolved. Also, because only midterm follow-up data are available, the long-term natural history of these lesions remains undefined. Of the larger series examining the Cox maze IV procedure (range, 94-250 patients), the maximum follow-up has ranged from 12 months to 3.6 years, with large variability. ${ }^{10-14}$ Furthermore, new technology and approaches have facilitated the advent of minimally invasive surgical AF ablation. Experience with this technology is even less mature (687 patients in 14 series) and only early-term results (follow-up range, 6-17 months) have been published. Only 10 of 16 studies have reported outcomes in adherence with current consensus, with success rates ranging from $57 \%$ to $88 \%{ }^{15}$ Although alternate technology and approaches to surgical AF ablation have continued to evolve and attempted to replicate the results from the Cox maze III procedure, it is imperative that standardized evaluations are undertaken to draw firm conclusions.

Although much focus on surgical AF ablation has been on the energy sources, lesion sets, and approaches, patient-related factors can influence greatly the outcomes, and all these factors need to be considered together and not in isolation. We observed the greatest success with CSM as an energy source; however, no difference were found between any single lesion set at $<5$ years postoperatively. However, when the energy source and lesion set were combined in the analysis, the Cox maze III procedure (cut and sew with the BA lesion set) proved the most effective. Preoperative paroxysmal AF, older age, and NYHA functional class III-IV were also independently predictive of recurrent AF, not only for the entire cohort, but also were most predictive $<5$ years after isolated mitral valve surgery. It was only until $>5$ years postoperatively that the Cox maze III procedure was independently predictive of greater success. Analyzing the outcomes of surgical AF ablation has become quite complex, and many more factors need to be evaluated than just the lesion set or energy source.

\section{Study Limitations}

The major limitation of the present series was the heterogeneity of the patient population, a common challenge in series examining the outcomes of surgical ablation of AF. We attempted to account for confounders by performing narrower subgroup analyses and performing a multivariate analysis and entering all pertinent variables for evaluation. In addition, we conformed to the current consensus statement in terms of the definition of AF type and lesion sets and reporting outcomes in an attempt to lessen the heterogeneity. The present study was a retrospective review and possessed all the inherent limitations of this type of study design. All rhythm outcomes were obtained from electrocardiographic reports. When a 24-hour Holter monitor was available, which was the minority of the time, we confirmed the rhythm observed on the ECG. Although the best monitoring modality has yet to be defined, electrocardiography has been shown to overestimate success by $>10 \%$ compared with long-term monitoring. ${ }^{16,17}$ Follow-up data were not available for all patients; thus, the outcomes we have reported might not reflect the true outcomes.

Event monitoring was discussed in the HRS consensus statement as the standard method to evaluate patients after surgical ablation of AF. We acknowledge that our use of electrocardiography was not in accordance with that statement. Although we do use event monitoring in the current era, for the evaluation of our patients after $\mathrm{AF}$ ablation before 2007, the year the HRS statement was published, we used electrocardiography, which was acceptable. However, our report spans 2 decades; thus, if a comparison will done with patients who have undergone a procedure used most commonly before the HRS statement in 2007, electrocardiography would still need to be used. Although studies have indicated that this might overestimate success, we decided to use this method consistently and homogeneously for all patients, with the hope that if an overestimation was present, it would be uniform across all patient populations. It would not make sense to use electrocardiographic follow-up for the maze patients who had undergone surgery 15 years earlier and than compare that with the event monitoring for patients who had had alternate energy sources used in the current era.

\section{CONCLUSIONS}

In our experience, the standard cut and sew Cox maze III operation has been the most reliable and effective method to 
ensure transmural atrial lesions and, thus, maximized the potential for ablation of AF. Furthermore, as observed in the present series, the Cox maze III procedure offers significantly greater freedom from AF compared with alternate energy sources and lesion sets. Patient factors, including risks and benefits, should always be considered when planning AF ablation to optimize the lesion set and energy source applied. Although we might consider isolated PVI to potentially be adequate for a patient with paroxysmal $\mathrm{AF}$, a more complete $\mathrm{BA}$ lesion set might be required for patients with more long-standing $\mathrm{AF}$ and complex valvular disease, in whom the pathogenesis of AF could be completely different. It is not clear whether newer procedures have definitively demonstrated equivalency to the Cox maze III procedure with limited series and follow-up data. Although these technologies and alternate approaches can be appropriate in select patients, the Cox maze III procedure remains the reference standard for the surgical treatment of $\mathrm{AF}$ and should still be considered, especially for patients for whom AF ablation is of critical importance.

\section{References}

1. Cox J, Schuessler RB, D'Agostino HJ Jr. The surgical treatment of atrial fibrillation. III. Development of a definitive surgical procedure. J Thorac Cardiovasc Surg. 1991;101:569-83.

2. Cox JL, Boineau JP, Schuessler RB, Kater KM, Lappas DG. Five-year experience with the maze procedure for atrial fibrillation. Ann Thorac Surg. 1993;56:814-24.

3. Stulak JM, Sundt TM III, Dearani JA, Daly RC, Orszulak TA, Schaff HV. Ten-year experience with the Cox-maze procedure for atrial fibrillation: how do we define success? Ann Thorac Surg. 2007;83:1319-25.

4. Edgerton ZJ, Edgerton JR. History of surgery for atrial fibrillation. Heart Rhythm. 2009;6:S1-4.

5. Shemin RJ, Cox JL, Gillinov AM, Blackstone EH, Bridges CR. Workforce on evidence-based surgery of the Society of Thoracic Surgeons: guidelines for reporting data and outcomes for the surgical treatment of atrial fibrillation. Ann Thorac Surg. 2007;83:1225-30.

6. Calkins H, Brugada J, Packer DL, Cappato R, Chen SA, Crijns HJ, et al, for the European Heart Rhythm Association (EHRA); European Cardiac Arrhythmia Society (ECAS); American College of Cardiology (ACC); American Heart Association (AHA); Society of Thoracic Surgeons (STS). HRS/EHRA/ECAS expert consensus statement on catheter and surgical ablation of atrial fibrillation: recommendations for personnel, policy, procedures, and follow-up: a report of the Heart Rhythm Society (HRS) task force on catheter and surgical ablation of atrial fibrillation. Heart Rhythm. 2007;4:816-61.

7. Gaynor SL, Diodato MD, Prasad SM, Ishii Y, Schuessler RB, Bailey MS, et al. A prospective, single-center clinical trial of a modified Cox-maze procedure with bipolar radiofrequency ablation. J Thorac Cardiovasc Surg. 2004;128:535-42.

8. Melby SJ, Zierer A, Bailey MS, Cox JL, Lawton JS, Munfakh N, et al. A new era in the surgical treatment of atrial fibrillation: the impact of ablation technology and lesion set on procedural efficacy. Ann Surg. 2006;244:583-92.

9. Stulak JM, Dearani JA, Sundt TM III, Daly RC, McGregor CGA, Zehr KJ, et al. Superiority of cut-and-sex technique for the Cox-maze procedure: comparison with radiofrequency ablation. J Thoracic Cardiovasc Surg. 2007;133:1023-7.

10. Saint LL, Bailey MS, Prasad S, Guthrie TJ, Bell J, Moon MR, et al. Cox-maze IV results for patients with lone atrial fibrillation versus concomitant mitral disease. Ann Thorac Surg. 2012;93:789-95.

11. Yanagawa B, Holmes SD, Henry L, Hunt S, Ad N. Outcome of concomitant Cox-maze III procedure using an argon-based cryosurgical system: a single-center experience with 250 patients. Ann Thorac Surg. 2013;95:1633-9.

12. Ad N, Henry L, Hunt S. The concomitant cryosurgical Cox-maze procedure using argon-based cryoprobes: 12 month results. J Cardiovasc Surg (Torino). 2011;52:593-9.
13. Weimar T, Schena S, Bailey MS, Maniar HS, Schuessler RB, Cox JL, et al. The Cox-maze procedure for lone atrial fibrillation: a single-center experience over 2 decades. Circ Arrhythm Electrophysiol. 2012;5:8-14.

14. Kim JS, Lee JH, Chang HW. Surgical outcomes of Cox-maze IV procedure using bipolar irrigated radiofrequency ablation and cryothermy in valvular heart disease. Korean J Thorac Cardiovasc Surg. 2011;44:18-24.

15. Mack MJ. Current results of minimally invasive surgical ablation for isolated atrial fibrillation. Heart Rhythm. 2009;6:S46-9.

16. Ad N, Henry L, Hunt S, Barnett S, Stone L. The Cox-Maze III procedure success rate: comparison by electrocardiogram, 24-hour Holter monitoring and long-term monitoring. Ann Thorac Surg. 2009;88:101-5.

17. Edgerton JR, Mahoney C, Mack MJ, Roper K, Herbert MA. Long-term monitoring after surgical ablation for atrial fibrillation: how much is enough? J Thorac Cardiovasc Surg. 2011;142:162-5.

\section{Discussion}

Dr Ralph J. Damiano, Jr (St Louis, Mo). Dr Stulak, thank you for providing me with the report and congratulations on a superb presentation.

This is a very interesting study, and I think it illustrates one of the problems with looking back at a long retrospective experience from either a single or multiple centers. One of the greatest problems with your data is that the groups were extremely heterogeneous, just as you have alluded, and it is almost impossible to account for all those variables when you examine your data.

Perhaps the most single important variable is the surgeon experience and technical proficiency with the different procedures. My first question for you is whether you controlled for the surgeon performing the ablation procedures? I know historically at least at your institution, Dr Schaff has been a real proponent of the cut and sew procedure. If he performed all the cut and sew operations and other surgeons with varying levels of experience performed the other ablation procedures, how did you take that into account?

Dr Stulak. That is a great point. We did not control for the surgeon. Just as I stated in the last line, I do not know how generalizable our data will be, because this was basically our experience. Actually 4 surgeons throughout the study period performed the CSM, with the 90-whatever percent performed by Dr Schaff; thus, this was almost a comparison of what he does during his mitral valve operations compared with 8 to 12 other surgeons during that same period using alternate energy sources. So, you were exactly right, it would be difficult to control for that.

But this is not the end game for us. This is just the beginning, studying how we can better evaluate new technology and control for confounders at the same time. I think I have learned a lot and will continue to do so.

Dr Damiano. No, I think that is a really important point. You really cannot underestimate that variable.

I will just share an anecdote from one of the large multicenter trials in which we recruited a number of centers, all with very experienced surgeons who all were trained to perform the Cox maze IV procedure. The center-to-center variability in the success rate, as adjudicated by an independent core laboratory, ranged from $0 \%$ to $100 \%$. You might say that this is either the greatest procedure ever invented or the worst. But it really is related to how it was performed. The take home message from your study should not be that one should always perform a Cox maze III procedure. Because it is interesting, even at your own institution, 
if the CSM was that great, how come you did not perform it more frequently?

Dr Stulak. No, absolutely. I think the message from our report is, is that results are different. Also, although we have this new technology, we should not become complacent and say, "Wow, we have this great technology." We can compare it with an operation we know has yielded wonderful results and for us to continue to evolve and always improve that technology. We are certainly not saying "let us go back in time," necessarily because of the reasons it was abandoned in the first place probably. However, I think there still is a niche for it, and I think it does serve, we have the most data for it; thus, I think it will serve as a comparator group as we move toward new technologies and approaches.

Dr Damiano. Yes, I think that is an excellent point, that it serves as a great reference standard.

My last question and comment on your data is that, although admittedly the guidelines were not published until 2007, when we present reports on the surgical ablation of AF it is not adequate just to present electrocardiograph follow-up data. We know that that really underestimates the rate. Do you have a subset of patients that met the minimum criteria for follow-up, which would be a 24-hour Holter or pacemaker interrogation, and have you studied your results when you have adequate follow-up data?

Dr Stulak. This is a great point. Unfortunately, we did not have Holter monitoring data for the comparator group, and we believe that using 2 different methods of rhythm evaluation would not have been appropriate. We have begun to follow patients with Holter monitoring during follow-up in the current era. However, if you use the same monitoring method for all patients, you would like to assume that it would overestimate the success for all patients. Thus, we wanted to at least not compare Holter versus old-time ECGs. So, you are right, although that was one caveat that I throw myself on the sword for in the presentation, we had to have similar comparator groups, at least for this analysis.

Dr Damiano. A final quick question. Many of the large studies have shown for both catheter and surgical ablation that LA size is a predictor of failure. I notice that did not come out in your multivariate analysis. Is that because you did not have enough data, particularly from the older part of your series, or was that really not a predictor of failure?

Dr Stulak. No, in our earlier report we saw a 55-mm cutoff. This did not come out. I would suggest that we did not have adequate echocardiographic data beforehand, either, in patients undergoing coronary artery bypass grafting. 